\title{
Surgical Techniques in Ophthalmology Series: Oculoplastic Surgery with DVD Rom Editor: John A. Long
}

\author{
2009, Hardcover ISBN:978-1-4160-3286-1 Saunders Elsevier
}

\author{
Shimon Rumelt \\ Received: 18 March 2010 /Accepted: 2 April 2010 /Published online: 16 May 2010 \\ (C) Springer-Verlag 2010
}

Keywords Surgical · Oculoplastic

This book is part of a series of surgical-procedure books in different subspecialties. It was written by a single experienced oculoplastic surgeon. This is a compact and concise book dealing with eyelid and orbital surgical procedures. It has a hard cover and was printed on high-quality glossy paper. The publisher did not save any efforts to produce a high-quality product. It contains multiple high-quality color photos demonstrating the different steps in the surgical techniques. Some photos require high skill or experience to differentiate between different tissues that are manipulated during surgery and marking these tissues with arrows would be welcome.

The 175-page book is divided into 20 chapters. Each chapter deals with a different disorder. Eyelid disorders are more emphasized than orbital ones. The book contains only the most common oculoplastics procedures. Many chapters include several approaches to each disorder but the book does not cover endoscopic surgeries of the lacrimal drainage pathways, orbit or face and aesthetic procedures. Each chapter is organized into a list of instruments that are required for each procedure, type of anesthesia, indications, surgical steps, complications, and suggestions for further reading, but it does not contain the pathophysiology of each disorder and the logic behind each

\section{S. Rumelt $(\bowtie)$}

Department of Ophthalmology,

Western Galilee-Nahariya Medical Center,

Nahariya, Israel

e-mail: shimon.rumelt@naharia.health.gov.il surgical approach. The book describes the procedures stepby-step and includes "clinical pearls" within boxes in each chapter bringing additional information and tips for better success. The clinical pearls, however, are spares, and the complications are only briefly mentioned, usually without emphasis on prevention and treatment. Some steps do not include all the information to perform them. For instance, the type of sutures for lateral tarsal strip and their positioning or a figure demonstrating the exact location of the fascia lataharvesting site is missing. Some data are absent, for example, the amount of levator resection for each millimeter of ptosis. Many types of flaps for eyelid reconstruction and the use of ear cartilage and other homologous grafts are not mentioned. Several steps were included to repair entropion, but each step may be used alone according to the etiology of the entropion, although applying all of them may enhance the surgical outcomes. The book ends with an index that facilitates the navigation between different topics. The CD-DVD is a superb companion to this book. It contains single short explained videos on each procedure. The clips are arranged in chapters and sections according to the book's chapters, which allow easy navigation. The videos are of superb quality. Similar titles contain step-by-step procedures have already been published (e.g., Mark R. Levine. Manual of Oculoplastic Surgery. 3rd Edition, Butterworth-Heinemann: Philadelphia, PA, 2003, 4th edition coming soon).

The book is designated for the trainee in ophthalmology and the general practitioner rather than for the oculoplastic surgeon. Trainees in otolaryngology, facial reconstructive surgery, and general plastics may also benefit. The book stands within the goals of the author to "help the readers enjoy the art and craft of surgery." 